\title{
The Effect of Dialysates and Ultrafiltrates of Plasma of Saline-Loaded Dogs on Toad Bladder Sodium Transport
}

\author{
Vardaman M. Buckalew, Jr., F. Jesus Martinez, and \\ Wesley E. Green \\ From the Department of Internal Medicine, Emory University School of \\ Medicine, Atlanta, Georgia 30303
}

A B S T R A C T In order to obtain direct evidence for the existence of a natriuretic hormone, dialysates and ultrafiltrates of plasma of dogs expanded with saline were tested for effects on sodium transport by the toad urinary bladder. Dialysate was obtained by dialysis of blood in vivo in a clinical dialyzer and by dialysis in vitro of small volumes of blood using a miniature model of the clinical dialyzer. Ultrafiltrates were prepared using selective molecular filters which permit passage of substances on the basis of molecular weight and three dimensional configuration.

Dialysates and ultrafiltrates of hydropenic dogs caused a change in toad bladder potential difference of $+1 \%$ and in short circuit current of $-5 \%$. In contrast, dialysates and ultrafiltrates from expanded dogs caused a change in potential difference of $-23 \%$ and in short circuit current of $-32 \%$, a highly significant difference. Onset of reduction of short circuit current occurred within 3-5 min, reaching a maximum in 10$20 \mathrm{~min}$. The effect was rapidly reversible, was specific for the serosal surface of the bladder, and could not be explained on the basis of nonspecific alterations in ionic composition or by dilutional effects. Ultrafiltrates of jugular vein plasma caused significantly more reduction of short circuit current than ultrafiltrates of femoral vein plasma. The data indicate the presence in plasma of saline-loaded dogs of a dialyzable inhibitor of toad bladder sodium transport. Ultrafiltrate studies using membranes of appropriate selectivity suggest the factor has a molecular weight of less than 3000 .

\section{INTRODUCTION}

The mechanisms regulating renal sodium excretion have received extensive study for many years. In a clas-

This work was presented in part at the National Meeting of the American Federation for Clinical Research, 4 May 1969, Atlantic City, N. J.

Received for publication 8 September 1969 and in revised form 19 December 1969. sic review article in 1957, Smith (1) suggested that some extra-adrenal hormonal system might be important in controlling tubular sodium reabsorption. Subsequently, de Wardener, Mills, Clapham, and Hayter (2) and Levinsky and Lalone (3) demonstrated that natriuresis after saline loading in the dog was primarily the result of decreased tubular sodium reabsorption. This finding suggested the possibility that a natriuretic hormone might be an important factor in saline diuresis.

In spite of subsequent efforts in a number of laboratories, the existence of a humoral inhibitor of renal tubular sodium reabsorption remains a matter of considerable controversy (4). Cross-circulation studies by Johnston and Davis (5) and Lichardus and Pearce (6) have been interpreted as indicating the presence of a transferable natriuretic factor in volume-expanded dogs. The studies of Bahlmann, McDonald, Ventom, and de Wardener (7) in which the effects of dilution by the expanding solution were carefully controlled, have been similarly interpreted. However, cross-circulation experiments reported by McDonald, Schrier, and Lauler (8) and by Levinsky (19) failed to demonstrate a significant natriuresis in recipient dogs. More recently Pearce, Lichardus, Sonnenberg, and Veress have reported similar negative studies in rats (10).

Cort, Dousa, Pliska, Lichardus, Safarova, Vranesic, and Rudinger (11) have reported extensive studies of a humoral natriuretic factor. Their results suggest that plasma of diuretic animals contains a low molecular weight polypeptide of neural origin, which causes natriuresis in cats and rats and inhibits sodium transport in the frog skin. However, most of the studies of these investigators have used a concentrate of plasma with a very high sodium concentration, the effects of which have not been fully evaluated in their bioassay systems. For this reason, their results are difficult to interpret. The work of Rector, Martinez-Maldonado, Kurtzman, Sellman, Oerther, and Seldin (12) showing a humoral inhibitor of proximal tubular sodium reabsorption by 
micropuncture techniques has not been reproducible (4).

In an attempt to obtain direct evidence of the existence of the postulated natriuretic hormone, we have studied the effects of dialysates and ultrafiltrates of plasma of saline-loaded dogs on the rate of active sodium transport in the toad urinary bladder. Our studies were based on the assumption that the postulated factor was dialyzable and the studies were designed to obtain the factor in a solution having a physiologic ionic composition. The results demonstrate that both dialysates and ultrafiltrates of plasma of dogs undergoing saline diuresis inhibit transmembrane potential difference and short circuit current of the toad bladder. The data suggest that acute saline loading in the dog is associated with a humoral factor of low molecular weight which has the capability of inhibiting active sodium transport in vitro and may be a natriuretic hormone.

\section{METHODS}

Female mongrel dogs weighing $10-20 \mathrm{~kg}$ were fed a cereal diet. Hydropenia was produced by food and water deprivation for $12-16 \mathrm{hr}$ before study and the dogs were divided into two groups.

Group I. 13 hydropenic dogs were anesthetized with pentobarbital $(25 \mathrm{mg} / \mathrm{kg}$ ), given heparin intravenously (30 $\mathrm{mg}$ initially followed by $10 \mathrm{mg} / \mathrm{hr}$ thereafter), and subjected to in vivo dialysis before, during, and after saline diuresis by the following procedure. Both jugular veins were cannulated and blood recirculated by a peristaltic pump at $80-120 \mathrm{ml} / \mathrm{min}$ through a Klung dialyzer having a membrane surface area of $0.5 \mathrm{~m}^{2}$ with a countercurrent flow pattern (13). The dialysate was $100 \mathrm{ml}$ of bicarbonate Ringer solution which was recirculated at the same rate. Ultrafiltration occurred at approximately $1-2 \mathrm{ml} / \mathrm{min}$ and was replaced by a constant infusion of isotonic saline. Hydropenic dogs were dialyzed for $60-90 \mathrm{~min}$, and an aliquot of dialysate removed (hydropenic dialysate). Saline diuresis was then induced by the administration of $0.9 \%$ saline intravenously, $500 \mathrm{ml}$ at $25 \mathrm{ml} / \mathrm{min}$ initially, followed by a constant infusion at $10 \mathrm{ml} / \mathrm{min}$. Urine was collected at 20-min intervals for the determination of urine flow (V). $\mathrm{V}$ increased from less than $1 \mathrm{ml} / \mathrm{min}$ to $2-10 \mathrm{ml} / \mathrm{min}$ during the saline infusion. Approximately $30-60 \mathrm{~min}$ after starting saline, the dialysate compartment of the dialyzer was rinsed with fresh dialysate and dialysis was performed for an additional $60-90 \mathrm{~min}$. An aliquot of this dialysate (diuretic dialysate) was collected at the end of this period. In four studies, the saline infusion was stopped; and after rinsing the dialysate compartment again, dialysis was continued for 60-90 min and an aliquot of dialysate was collected (postdiuretic dialysate). In five group I dogs, diuretic jugular venous plasma was obtained for in vitro dialysis, and in two additional dogs, ultrafiltrates of jugular venous plasma drawn during both hydropenia and at the conclusion of the diuretic dialysis procedure were prepared.

Group II. 18 dogs were anesthetized and given saline intravenously according to the same protocol outlined for group I, but they did not undergo in vivo dialysis and hence did not receive heparin systemically. In group II experiments, hydropenic plasma was obtained before saline infusion and diuretic plasma was drawn between 90 and $200 \mathrm{~min}$ after starting the saline infusion. In five experiments, postdiuretic jugular venous plasma was obtained between 60 and $100 \mathrm{~min}$ after the saline infusion was stopped and ultrafiltrates prepared as described below. In seven experiments, plasma from diuretic dogs was obtained simultaneously from the jugular and femoral veins. Plasma obtained in these experiments was processed in vitro by the following methods.

In vitro dialysis. Four samples of hydropenic jugular venous plasma and four of diuretic plasma were dialyzed in a miniature model of the Klung having a membrane surface area of $50 \mathrm{~cm}^{2}$ (14). Selection of specimens for this procedure was on a random basis. The four hydropenic samples were from group II dogs. Three of the four diuretic samples were from group I dogs, and the other was from one of the group II dogs from which hydropenic blood was obtained. Since the results did not vary between the groups, the data were considered collectively. Plasma was separated and dialyzed at $4^{\circ} \mathrm{C}$ against bicarbonate Ringer solution. $10-20 \mathrm{ml}$ of plasma and dialysate were recirculated at $1.0-1.5 \mathrm{ml} / \mathrm{min}$, for $16-19 \mathrm{hr}$. To determine the possible influence of dialysis time on the effect of dialysate on the toad bladder, jugular plasma samples from four additional diuretic dogs were dialyzed for only $2-4 \mathrm{hr}$.

Ultrafiltrates. Plasma ultrafiltrates were prepared with Diaflow membranes. ${ }^{1}$ These membranes have been shown to be selective molecular filters, allowing passage of substances on the basis of molecular weight and configuration (15). Two types were used in these studies, the UM-10 which has a molecular weight cutoff of approximately 10,000 , and the UM-2 which has a molecular weight cutoff of approximately 1000 . Plasma was ultrafiltered at $4^{\circ} \mathrm{C}$ in a stirred pressure cell using compressed air at $50 \mathrm{lb} . / \mathrm{sq}$. in. UM-10 ultrafiltrates were obtained from ten diuretic dogs and in six of these dogs paired hydropenic UM-10 ultrafiltrates were studied. In the other four dogs a paired hydropenic sample was obtained and was either a UM-2 ultrafiltrate or a $50 \mathrm{~cm}^{2}$ Klung dialysate. In addition, diuretic jugular plasma ultrafiltrates prepared with UM-2 membranes from five dogs were studied.

The ionic concentration of dialysates and ultrafiltrates were determined by the following methods: sodium and potassium on a lithium internal standard flame photometer; chloride by the AutoAnalyzer ${ }^{2}$ using a modification of the procedure described by Zall, Fisher, and Garner (16) ; calcium by the AutoAnalyzer method of Kessler and Wolfman (17) ; glucose by the AutoAnalyzer method adapted from Hoffman (18) ; osmolality by freezing point depression; and pH by a glass electrode.

Dialysates and ultrafiltrates were stored at $-5^{\circ} \mathrm{C}$ until tested for effects on toad bladder. Although most studies were performed within 2 wk after preparation of the dialysate or ultrafiltrate, several samples stored at $-5^{\circ} \mathrm{C}$ for up to 7 months gave results similar to those obtained with fresh samples. Dialysates and ultrafiltrates were diluted with distilled water to the same osmolality as amphibian Ringer solution before testing in the toad bladder.

Toad bladder. Studies were performed during all four seasons of the year from the fall of 1968 to the summer of 1969. Columbian toads, ${ }^{3}$ kept on Sani-cel ${ }^{4}$ moistened with tap water, were pithed and hemibladders removed and placed in a round, two-compartment lucite chamber with an exposed membrane surface area of $3.5 \mathrm{~cm}^{2}$. Each quarter-

\footnotetext{
${ }^{1}$ Amicon Corp., Scientific Systems Div., Lexington, Mass.

2 Technicon Corporation, Ardsley, N. Y.

8 The Pet Farm, Miami, Fla.

- Paxton Processing Co., Inc., Paxton, Ill.
} 
TABLE I

Ionic Composition of Dialysates*

\begin{tabular}{|c|c|c|}
\hline \multirow[b]{2}{*}{$\mathrm{Na}, m E q /$ liter } & $\begin{array}{l}\text { Hydropenic } \\
\text { dialysate }\end{array}$ & $\begin{array}{c}\text { Diuretic } \\
\text { dialysate }\end{array}$ \\
\hline & $105 \pm 1$ & 106 \\
\hline $\mathrm{K}, m E q /$ liter & $2.4 \pm 0.2$ & $2.4 \pm 0.3$ \\
\hline $\mathrm{Cl}, m E q /$ liter & $88 \pm 2$ & $96 \pm 2$ \\
\hline $\mathrm{Ca}, m \mathrm{M} /$ liter & $0.7 \pm 0.2$ & $0.8 \pm 0.1$ \\
\hline Glucose, $m g / 100 m l$ & $92 \pm 24$ & $61 \pm 28$ \\
\hline Osm, $\mathrm{mOsm} / \mathrm{kg}$ & $212 \pm 1$ & $213 \pm 2$ \\
\hline $\mathrm{pH}$ & $7.46 \pm 0.07$ & $7.32 \pm 0.07$ \\
\hline $\mathrm{HCO}_{3}, m \mathrm{M} /$ liter $\ddagger$ & $15 \pm 3$ & $11 \pm 2$ \\
\hline
\end{tabular}

* Data are mean \pm SD for 10 samples in each group.

¥ Calculated from Henderson-Hasselbalch equation assuming pK of 6.10 and $\mathrm{PCO}_{2}$ of $22.5 \mathrm{~mm} \mathrm{Hg}$.

bladder was bathed on mucosal and serosal surfaces by 4 $\mathrm{ml}$ of amphibian bicarbonate Ringer solution, gassed with $97 \% \mathrm{O}_{2}$ and $3 \% \mathrm{CO}_{2}$, having the following composition (in millimolar units): $\mathrm{NaCl}, 83.0 ; \mathrm{NaHCO}_{3}, 25.0 ; \mathrm{Na}_{2} \mathrm{HPO}_{4}$, $2.5 ; \mathrm{KH}_{2} \mathrm{PO}_{4}, 0.5 ; \mathrm{KCl}, 2.0 ; \mathrm{CaCl}_{2}, 1.6$; and glucose, 5.5. Bladders were kept open circuited, and potential difference (PD) and short circuit current (SCC) were monitored intermittently on a Keithley Model 151 electrometer $^{5}$ through an external circuit similar to that described by Finn, Handler, and Orloff (19). Bladders having a PD of less than $20 \mathrm{mv}$ and a SCC of less than $60 \mu \mathrm{a}$ were discarded. The Ringer solution bathing all four surfaces of each hemibladder was exchanged for fresh Ringer solution 20-60

${ }^{5}$ Keithley Instruments, Cleveland, Ohio. min after placing the bladders in the chamber. After a control period of at least $30 \mathrm{~min}$ during which a stable baseline for PD and SCC was established, the Ringer solution bathing the serosal or mucosal surface of one quarterbladder was replaced with $4 \mathrm{ml}$ of a diluted dialysate or ultrafiltrate. Simultaneously, the bath of the corresponding surface of the remaining quarter-bladder was replaced with fresh Ringer solution.

Changes in PD and SCC on the test side were corrected for any spontaneous changes on the control side and expressed as per cent change from base line $30 \mathrm{~min}$ after addition of the samples. It was assumed that SCC closely approximated the rate of active sodium transport by the bladder (20). Statistical analysis was performed according to standard procedure (21).

\section{RESULTS}

Dialysate studies. The ionic composition of 10 samples of hydropenic and diuretic dialysate which had been diluted to isotonicity with the Ringer solution is shown in Table I. The mean $\mathrm{pH}$ and bicarbonate concentration are lower and the mean chloride concentration is higher in diuretic dialysate than in hydropenic dialysate.

Fig. 1 shows a typical study of the effect of hydropenic dialysate on short circuit current. Hydropenic dialysate was placed on the serosal surface of one quarter-bladder at time zero, and at the same time fresh Ringer solution was placed on the serosal surface of the opposite quarter-bladder. As can be seen from the figure, no significant change in SCC occurred for up to $50 \mathrm{~min}$.

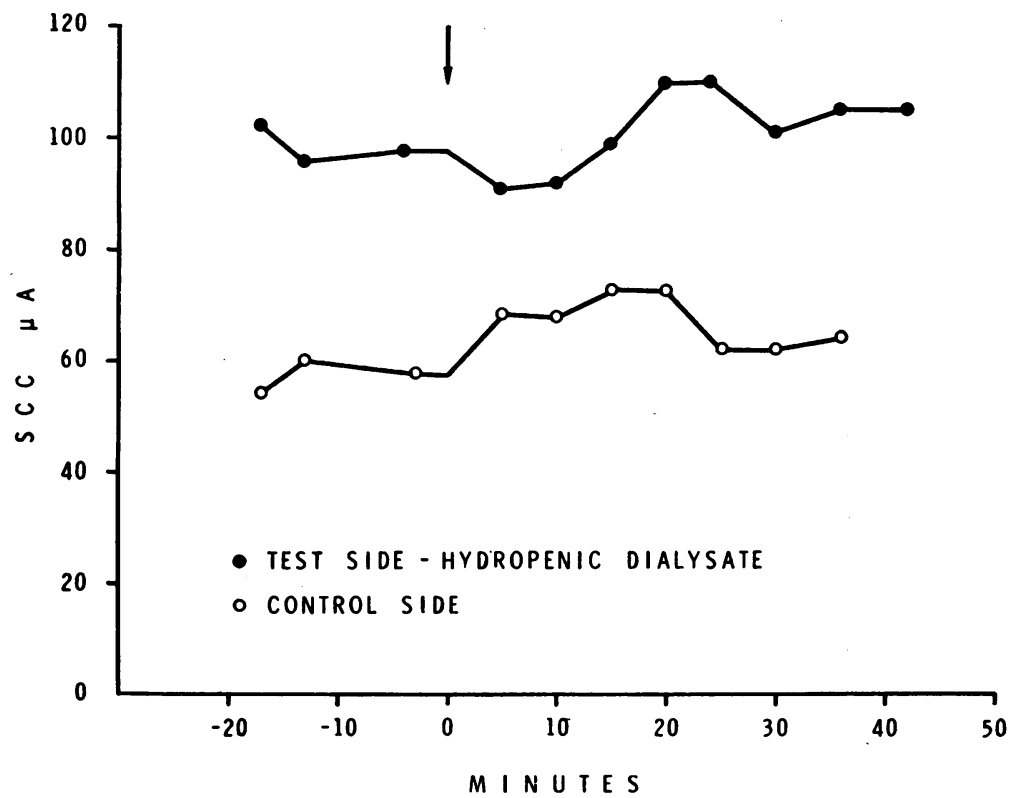

Figure 1 Effect of hydropenic dialysate on SCC in toad bladder. At time zero (arrow), $4 \mathrm{ml}$ of dialysate was added to "test side" and an equal volume of fresh Ringer's added to "control side." There was no significant change from steady-state values on either test or control sides. 


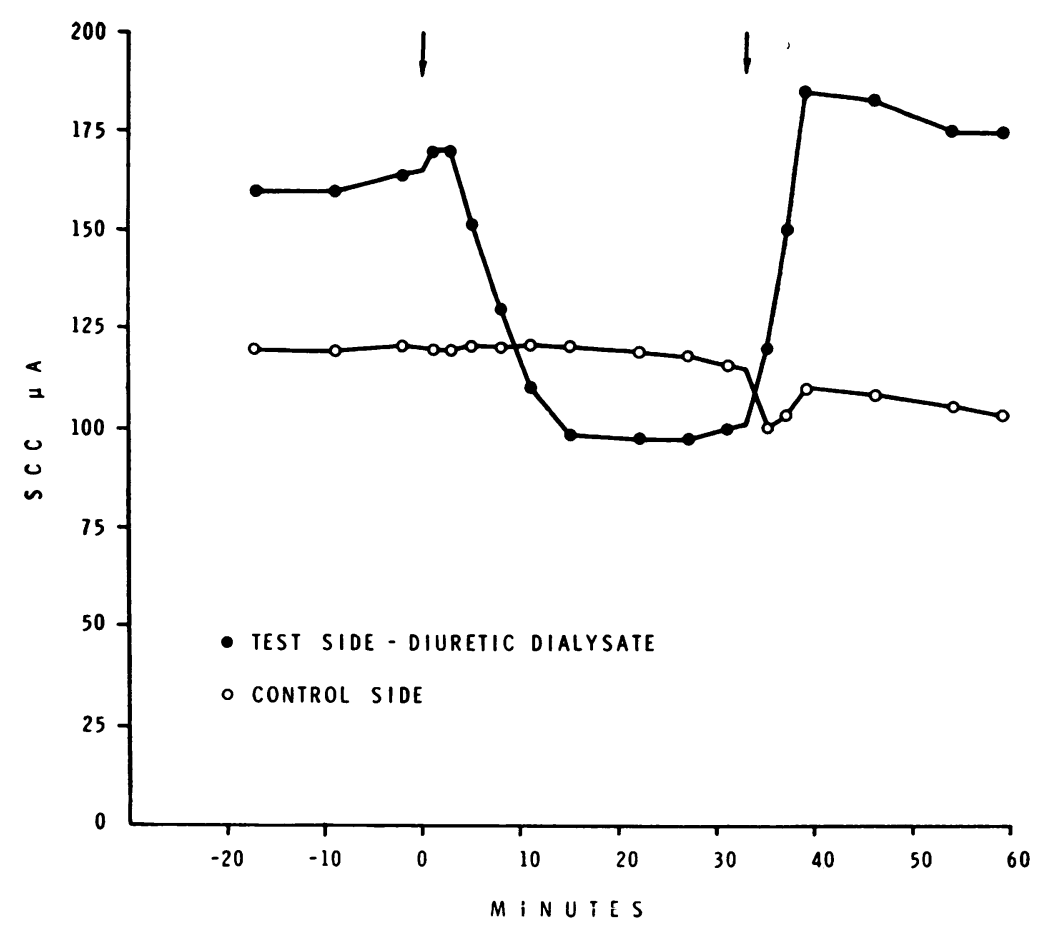

FIGURE 2 Effect of diuretic dialysate on SCC in toad bladder. Experiment was similar to that shown in Fig. 1.35 min after adding dialysate (second arrow) the serosal bath on both test and control sides was replaced by fresh Ringer's. Diuretic dialysate caused a reversible decrease of SCC of approximately $35 \%$.

Fig. 2 shows the results of a study following a similar procedure except that diuretic dialysate was used. After addition of the test sample SCC rose slightly initially, then began to fall rapidly, approximately 3-5 min after adding the dialysate. SCC reached a stable plateau approximately $35 \%$ below base line values after $10 \mathrm{~min}$, while no significant change occurred on the opposite side. After $35 \mathrm{~min}, 4 \mathrm{ml}$ of fresh Ringer solution was placed on the serosal side of both quarter-bladders and a rapid rise in SCC to values slightly higher than base line occurred on the test side.

Table II shows the effect of 13 hydropenic and diuretic dialysates on toad bladder $\mathrm{PD}$ and SCC. The results are shown as the per cent change from base line $30 \mathrm{~min}$ after addition of the samples corrected for any spontaneous change on the control side. The hydropenic samples caused a mean change in PD of $1 \pm 2 \%$ and in SCC of $-5 \pm 2 \%$. In contrast, the diuretic samples caused a mean change in PD of $-23 \pm 2 \%$ and in SCC of $-31 \pm 3 \%$. The difference between these two groups is significant at the 0.001 level. Also shown in the table is the effect of postdiuretic dialysate obtained in four of the experiments. In each case, the effect of postdiuretic dialysate on PD and SCC was less than the diuretic sample, and the mean for postdiuretic dialysate was significantly less than the mean for diuretic dialysate.

Table II also shows the effect of five samples of diuretic dialysate placed on the mucosal surface of the bladder, compared to the previously shown effect of serosal application. Mucosal application caused a mean change in PD of $+12 \%$ and in SCC of $-5 \%$, indicating no significant inhibition of active sodium transport.

Table III shows the effect of dialysates obtained using the miniature model of the Klung on the toad bladder. Four samples of diuretic and hydropenic plasma were dialyzed for 16-19 $\mathrm{hr}$ and four samples of diuretic plasma were dialyzed for only $2-4 \mathrm{hr}$. Diuretic dialysates obtained after 2-4 hr, and hydropenic dialysates had no effect on PD and SCC. Dialysates of diuretic plasma obtained after 16-19 $\mathrm{hr}$ dialysis caused a mean change in PD of $-23 \pm 5 \%$, and in SCC of $-29 \pm 3 \%$, which was similar to that obtained with large Klung diuretic dialysates.

Ultrafiltrates studies. Table IV shows the effect on PD and SCC of UM-10 membrane ultrafiltrates of jugular plasma from 10 dogs. Samples prepared from hydropenic plasma caused a mean change in PD of $2 \pm 4 \%$ and in SCC of $-6 \pm 4 \%$, whereas those from diuretic plasma caused a mean change in PD of -23 
TABLE II

Effect of $0.5 \mathrm{M}^{2}$ Klung Dialysates on Toad Bladder PD and SCC

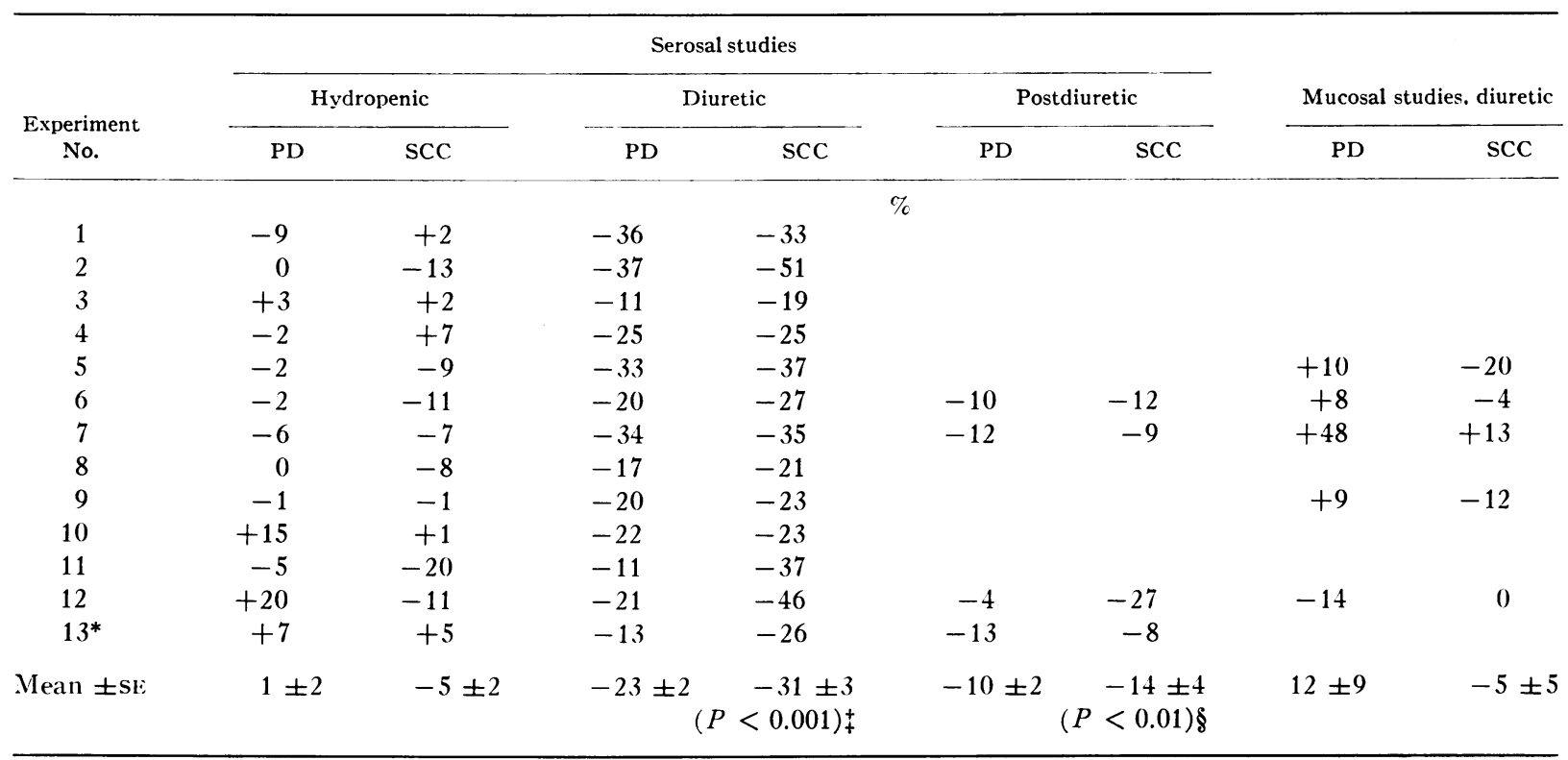

Data are expressed as the per cent change $30 \mathrm{~min}$ after placing the sample in the chamber, corrected for spontaneous changes on the control side. Serosal studies show the effect of hydropenic, diuretic, and postdiuretic dialysate. Mucosal studies show the effect of diuretic dialysate only.

* Diuresis produced by Ringer solution instead of saline.

$\ddagger$ Difference in PD and SCC between hydropenic and diuretic dialysate.

$\S$ Difference in PD and SCC between diuretic and postdiuretic dialysate.

$\pm 3 \%$ and in $\mathrm{SCC}$ of $-33 \pm 3 \%$. The difference between the two groups is highly significant $(P<0.001)$. In five dogs of this group (experiments $2,3,4,6$, and 9) a postdiuretic ultrafiltrate of jugular venous plasma was studied for effects on the toad bladder. Four of these were UM-10 and one was a UM-2 ultrafiltrate. These samples caused a mean change in $\mathrm{PD}$ of $-14 \pm 5 \%$ and in SCC of $-15 \pm 8 \%$. In each case the postdiuretic sample caused less inhibition of sodium transport than the diuretic sample and the mean difference between the paired samples is significant $(P<0.05)$.

TABLE III

Effect of Minature Klung Dialysates on PD and SCC*

\begin{tabular}{|c|c|c|c|c|}
\hline \multirow{2}{*}{$\begin{array}{l}\text { Dialysis } \\
\text { time }\end{array}$} & \multicolumn{2}{|c|}{$\begin{array}{l}\text { Diuretic plasma } \\
\text { dialysate }\end{array}$} & \multicolumn{2}{|c|}{$\begin{array}{c}\text { Hydropenic } \\
\text { plasma dialysate }\end{array}$} \\
\hline & PD & SCC & PD & SCC \\
\hline$h r$ & & $\%$ & & \\
\hline $2-4$ & $-1 \pm 2$ & $-2 \pm 3$ & & \\
\hline $16-19$ & $-23 \pm 5$ & $-29 \pm 3$ & $3 \pm 2$ & $0 \pm 3$ \\
\hline
\end{tabular}

Data are means $\pm \mathrm{SE}$ of four experiments in each group, and are expressed as in Table II.

* Membrane surface area was $50 \mathrm{~cm}^{2}$.
Also shown in Table IV is the effect of UM-2 membrane ultrafiltrates of diuretic jugular plasma from five dogs on PD and SCC. There is no difference between the effect of these ultrafiltrates and the diuretic ultrafiltrates obtained using the UM-10 membrane $(P>0.3)$.

In seven dogs diuretic plasma was drawn simultaneously from both the jugular and femoral veins. A comparison of the effects of these samples on toad bladder $\mathrm{PD}$ and SCC is shown in Table V. Jugular diuretic ultrafiltrate caused a mean fall in PD of $-22 \pm 3 \%$ and in SCC of $-33 \pm 3 \%$, whereas simultaneously drawn femoral dialysate caused a mean fall in PD of $-10 \pm 4 \%$ and in SCC of $-18 \pm 3 \%$. The difference between these two means is significant $(P<0.05)$ and the mean difference between the paired samples shown in Table $\mathrm{V}$ is also significant $(P<0.02)$. Jugular dialysate caused a greater fall in PD and SCC than did femoral dialysate in six of seven pairs and the effect of four of the seven femoral dialysates was indistinguishable from that of hydropenic dialysate.

\section{DISCUSSION}

These studies demonstrate that dialysates and ultrafiltrates of plasma of volume-expanded dogs inhibit toad bladder PD and SCC. Assuming that SCC ac- 
TABLE IV

Effect of Ultrafiltrates of Jugular Vein Plasma on Toad Bladder PD and SCC

\begin{tabular}{|c|c|c|c|c|c|c|c|}
\hline \multirow{3}{*}{$\begin{array}{l}\text { Experiment } \\
\text { No. }\end{array}$} & \multicolumn{4}{|c|}{ UM-10 Membrane } & \multirow{3}{*}{$\begin{array}{l}\text { Experiment } \\
\text { No. }\end{array}$} & \multirow{2}{*}{\multicolumn{2}{|c|}{$\begin{array}{c}\text { UM-2 Membrane, } \\
\text { diuretic }\end{array}$}} \\
\hline & \multicolumn{2}{|c|}{ Hydropenic } & \multicolumn{2}{|c|}{ Diuretic } & & & \\
\hline & $\mathrm{PD}$ & scc & $\mathrm{PD}$ & $\mathrm{scC}$ & & $\mathrm{PD}$ & SCC \\
\hline & \multicolumn{2}{|c|}{$\%$} & \multicolumn{2}{|c|}{$\%$} & & \multicolumn{2}{|c|}{$\%$} \\
\hline 1 & +28 & 0 & -29 & -39 & $\mathrm{~A}$ & -19 & -25 \\
\hline 2 & +8 & -2 & -28 & -38 & B & -15 & -23 \\
\hline 3 & +2 & -10 & -20 & -26 & $\mathrm{C}$ & -20 & -33 \\
\hline 4 & -2 & $-9^{*}$ & -13 & -22 & $\mathrm{D}$ & -22 & -36 \\
\hline 5 & +5 & $-3^{*}$ & -29 & -37 & $\mathrm{E}$ & -27 & -39 \\
\hline 6 & -17 & -33 & -27 & -40 & & & \\
\hline 7 & -10 & -29 & -20 & -30 & & & \\
\hline 8 & +7 & $+4 \ddagger$ & -13 & -33 & & & \\
\hline 9 & -5 & $+6 \S$ & -39 & -48 & & & \\
\hline 10 & +1 & +12 & -13 & -20 & & & \\
\hline Mean $\pm \mathrm{SE}$ & $2 \pm 4$ & $\begin{array}{c}-6 \pm 4 \\
(P\end{array}$ & $\frac{-23 \pm 3}{1) \|}$ & $-33 \pm 3$ & & $\begin{array}{r}-21 \pm 2 \\
(P\end{array}$ & $\begin{array}{l}-31 \pm 3 \\
0.3) \uparrow\end{array}$ \\
\hline
\end{tabular}

Data are expressed as in Table II.

* UM-2 membrane ultrafiltrates.

$\ddagger 0.5 \mathrm{M}^{2}$ Klung dialysate.

$\$ 50 \mathrm{~cm}^{2}$ Klung dialysate.

|| Difference in PD and SCC between hydropenic and diuretic ultrafiltrates.

- Difference in PD and SCC between diuretic UM-10 ultrafiltrates and diuretic UM-2 ultrafiltrates.

curately reflects the rate of active sodium transport by the bladder under the conditions of these studies, the results indicate that active sodium transport is inhibited by some property of these dialysates and ultrafiltrates.

The inhibition of sodium transport might have been due to $(a)$ some nonspecific alteration in ionic concentration of diuretic dialysates, $(b)$ dilution by the saline infusion of some factor or factors of plasma which tended to increase sodium transport, or $(c)$ a factor or factors which specifically inhibits active sodium transport.

TABLE V

Comparison of Effect on PD and SCC of Ultrafiltrates of Diuretic Plasma Drawn Simultaneously from Jugular and Femoral Veins

\begin{tabular}{|c|c|c|c|c|c|c|}
\hline \multirow{2}{*}{$\begin{array}{c}\text { Experiment } \\
\text { No. }\end{array}$} & \multicolumn{3}{|c|}{ PD } & \multicolumn{3}{|c|}{$\mathrm{scC}$} \\
\hline & $\mathrm{J}$ & F & $\Delta$ & $\mathrm{J}$ & F & $\Delta$ \\
\hline & & & ? & & & \\
\hline 1 & -13 & -2 & -11 & -33 & -14 & -19 \\
\hline 2 & -39 & -12 & -27 & -48 & -23 & -25 \\
\hline $3^{*}$ & -15 & +1 & -16 & -21 & -15 & -6 \\
\hline 4 & -27 & -16 & -11 & -40 & -32 & -8 \\
\hline 5 & -13 & -8 & -5 & -22 & -2 & -20 \\
\hline 6 & -28 & -30 & +2 & -38 & -42 & +4 \\
\hline 7 & -20 & -3 & -17 & -30 & +1 & -31 \\
\hline Mean $\pm \mathrm{SE}$ & $-22 \pm 3$ & $-10 \pm 4$ & $\begin{array}{l}-12 \pm 3 \\
<0.01)^{\dagger}\end{array}$ & $-33 \pm 3$ & $-18 \pm 5$ & $\begin{array}{l}-15 \pm 4 \\
<0.02) \ddagger\end{array}$ \\
\hline
\end{tabular}

Data are expressed as in Table II. J, jugular; F, femoral; $\Delta$, difference between jugular and femoral values.

* UM-2 membrane ultrafiltrates. The remainder of the samples were UM-10 membrane ultrafiltrates.

$\ddagger$ Significance of the difference between jugular and femoral values. 
Measurements of important ionic constituents of dialysate showed a lower mean $\mathrm{pH}$ of diuretic dialysate compared to hydropenic dialysate (Table I). It is unlikely that the range of $\mathrm{pH}$ observed in diuretic dialysate would have had an effect by itself on sodium transport (22). Furthermore, there was overlap in the data, so that some hydropenic samples showing no inhibition of SCC had similar $\mathrm{pH}$ to some diuretic samples showing inhibition of SCC. However, to evaluate further the possible effect of alterations in dialysate $\mathrm{pH}$ on $\mathrm{SCC}$, one dog was expanded with bicarbonate Ringer solution rather than saline to minimize the fall in $\mathrm{pH}$ of diuretic dialysate. Similar results were obtained as indicated in Table II. In addition, three hydropenic dialysates and one hydropenic ultrafiltrate were titrated to the $\mathrm{pH}$ range of the diuretic samples by the addition of $0.1 \mathrm{~N}$ hydrochloric acid, and the effects on the toad bladder were then compared to those effects obtained with untreated samples. The four untreated samples had a mean $\mathrm{pH}$ of $7.46 \pm 0.05\left(\mathrm{P}_{\mathrm{co}_{2}}=22.5\right)$ and caused a mean change in PD of $-1 \pm 5 \%$, and in SCC of $-1 \pm 3 \%$. After titrating these samples to a mean $\mathrm{pH}$ of $7.33 \pm 0.01$, they caused a mean change in PD of $+2 \pm 5 \%$ and in SCC of $+1 \pm 4 \%$. Thus, the lower $\mathrm{pH}$ of the diuretic dialysates does not account for the inhibition of SCC.

Additional evidence that a change in plasma composition secondary to the saline infusion was not responsible for the effects of diuretic dialysates on the toad bladder is also provided by the miniature Klung studies. Alexander and Galletti have shown that, in contrast to the plasma clearance of inorganic ions, plasma clearance of macromolecules by cuprophane membranes in the Klung dialyzer decreases as molecular weight increases (23). As a result, as dialysis time increases. the amount of any given macromolecule transferred to the dialysate increases. Thus, if the inhibiting property of diuretic dialysate were due to a dialyzable macromolecule, rather than to a nonspecific ionic alteration. the appearance of the inhibitory property of diuretic dialysate would be related to the length of dialysis time. The data in Table II show that dialysates of diuretic plasma obtained after $2-4 \mathrm{hr}$ 's dialysis time in the miniature Klung had no effect on SCC whereas those obtained after 16-19 hr had effects similar to diuretic dialysates obtained from the large Klung. This result demonstrates that the property of diuretic dialysate which inhibits SCC required more than $4 \mathrm{hr}$ dialysis time in a $50 \mathrm{~cm}^{2}$ Klung to be detected. This is longer than would be necessary for any alteration in ionic composition due to the saline infusion to be fully reflected in the dialysate. Furthermore, this result would not be expected if the inhibition of SCC were due to dilution of some natriferic humoral factor.
Possible differences in metabolic substrate concentrations among the dialysates were not controlled in these studies. Although the mean glucose concentration in the diuretic dialysate was lower than in hydropenic dialysate (Table I), it seems unlikely that dilution of glucose or of other metabolic substrate concentrations could account for these results for several reasons. First, as was the case with $\mathrm{pH}$, there was considerable overlap in glucose concentrations between diuretic and hydropenic samples. Secondly, bladders exposed to substrate-free media show a gradual decline in SCC, not a rapid fall as shown in these studies (24). Furthermore, the results of the miniature Klung studies (Table III) showing inhibition of SCC after $16 \mathrm{hr}$ but not after $4 \mathrm{hr}$ of dialysis would not be expected if the inhibition were due to low substrate concentration since. if anything, there would be more substrate present in the dialysate after $16 \mathrm{hr}$ than after $4 \mathrm{hr}$. Finally, we tested the effect on SCC of acute substrate deprivation by substituting the glucose-enriched Ringer solution bathing the serosal surface of several bladders with an equal volume of glucose-free Ringer solution. During a $35 \mathrm{~min}$ period of observation after this procedure, there were minimal changes in SCC.

These results, together with the studies of plasma ultrafiltrates, suggest that plasma of volume-expanded dogs contains a factor or factors which inhibits sodium transport of the toad urinary bladder. The upper limit of the molecular weight of this factor can be estimated from the Diaflow membrane experiments. These membranes have been shown to be selective molecular filters. allowing passage of substances on the basis of molecular weight and configuration (15). Assuming that this property of Diaflow membranes is applicable to the conditions of this study, the results summarized in Table IV suggest that the molecular weight of the factor inhibiting SCC is probably no greater than $3000 .^{\circ}$

The pattern of inhibition of SCC was similar in all studies. The onset of inhibition was rapid (within 3-5 $\min$ ), the inhibition reached a stable plateau in 10-20 min and was rapidly reversible (Fig. 2). In addition. the effect was specific for the serosal surface of the bladder (Table II). In this respect, the effect of this factor on toad bladder sodium transport is similar to that of vasopressin and oxytocin (20) and unlike that of aldosterone (25), which requires a lag time of approximately $1 \mathrm{hr}$ to exert its effect.

Some explanation is required for the fact that ultrafiltrates and dialysates caused the same degree of inhibition of sodium transport (Tables II and IV). The

\footnotetext{
${ }^{\circ}$ The specifications for the UM-2 membrane indicate an average molecular weight cutoff of 1000 . However, molecules as large as 3000 might pass through the membrane depending on their three dimensional configuration (Blatt, W. F. Personal communication)
} 
concentration of the factor in ultrafiltrates should closely approximate that in plasma, whereas the concentration in dialysates could only approach half that of plasma. This suggests that inhibition of sodium transport by the factor reaches a maximum at less than half the concentration present in plasma. Preliminary studies in which serial dilutions of ultrafiltrates have been compared for effects on sodium transport are consistent with this interpretation.

The studies comparing the effect of ultrafiltrates of jugular and femoral plasma were performed in an attempt to gain some knowledge of the site of origin of the sodium transport inhibitor. These studies show more inhibition of SCC by jugular plasma ultrafiltrates in six of seven paired studies. Furthermore, in four of the seven studies, the effect of femoral vein ultrafiltrates was indistinguishable from the effect of hydropenic ultrafiltrates. These results strongly suggest that femoral plasma contains a lower concentration of the factor than does jugular plasma, and the results are compatible with the interpretation that the factor originates in some structure in the head or neck. These studies also provide further evidence against the possibility that the inhibitory property of plasma is due to some nonspecific dilutional change resulting from the saline infusion, since any dilutional effects would likely be similar in both jugular and femoral plasma.

Because of the consistent ordering of the experiments such that controls always preceded experimental periods, it is possible that the transport inhibitor might have appeared and disappeared in plasma spontaneously as a function of time. It can be demonstrated that the presence of the factor was a function of the saline infusion and not of time by comparing the results of group I versus group II experiments. In 13 group I experiments ( Table II) the control period from the time of induction of anesthesia to the end of the hydropenic dialysis and the beginning of saline infusion was approximately 100$160 \mathrm{~min}$. In contrast, in the 13 group II experiments (Table IV) the control period from the induction of anesthesia to the beginning of saline infusion was only 10-34 min, so that there was overlap with respect to time between the experimental period in group II studies and the control period in group I studies. This is illustrated by the data in Table VI comparing a group I study (experiment 12, Table II, and experiment $\mathrm{A}$, Table IV) with a group II study (experiment E, Table IV). In the group II study the control period lasted only $30 \mathrm{~min}$ so that a diuretic ultrafiltrate, showing inhibition of SCC, was obtained $130 \mathrm{~min}$ after beginning the experiment and corresponded closely with respect to time to the hydropenic sample in the group I experiment which did not inhibit sodium transport. Similarly, a postdiuretic ultrafiltrate obtained $328 \mathrm{~min}$ after starting
TABLE VI

Comparison between Representative Group I and Group II Experiments

\begin{tabular}{|c|c|c|c|c|c|c|}
\hline \multirow[b]{3}{*}{ Time } & \multicolumn{6}{|c|}{ Experiment } \\
\hline & \multicolumn{3}{|c|}{ Group I } & \multicolumn{3}{|c|}{ Group II } \\
\hline & $\begin{array}{l}\text { Blood } \\
\text { sample }\end{array}$ & $\mathrm{PD}$ & scc & $\begin{array}{l}\text { Blood } \\
\text { sample }\end{array}$ & PD & $\mathrm{sCC}$ \\
\hline $\min$ & \multicolumn{3}{|c|}{$\%$} & \multicolumn{3}{|c|}{$\%$} \\
\hline 0 & \multicolumn{3}{|c|}{$\begin{array}{l}\text { Pentobarbital anes- } \\
\text { thesia }\end{array}$} & \multicolumn{3}{|c|}{$\begin{array}{l}\text { Pentobarbital anes- } \\
\text { thesia }\end{array}$} \\
\hline 20 & & & & $\mathrm{BO}$ & +4 & -12 \\
\hline 28 & & & & \multirow{2}{*}{\multicolumn{3}{|c|}{$\begin{array}{l}\text { Begin saline infusion } \\
25 \mathrm{ml} / \mathrm{min} \\
\text { Decrease infusion to } \\
10 \mathrm{ml} / \mathrm{min}\end{array}$}} \\
\hline 48 & & & & & & \\
\hline 55 & \multicolumn{3}{|c|}{$\begin{array}{l}\text { Start hydropenic dialy- } \\
\text { sis }\end{array}$} & & & \\
\hline 130 & & & & $\mathrm{~B} 1$ & -27 & -39 \\
\hline 136 & $\mathrm{BO}$ & +2 & -9 & & & \\
\hline 138 & \multicolumn{6}{|c|}{$\begin{array}{l}\text { Begin Ringer infusion } \\
25 \mathrm{ml} / \mathrm{min}\end{array}$} \\
\hline 158 & \multicolumn{6}{|c|}{$\begin{array}{l}\text { Decrease infusion to } \\
10 \mathrm{ml} / \mathrm{min}\end{array}$} \\
\hline 210 & \multicolumn{6}{|c|}{ Start diuretic dialysis } \\
\hline 220 & & & & B2 & -13 & -50 \\
\hline 228 & & & & Stop i & usion & \\
\hline 305 & $\mathrm{~B} 1$ & -19 & -25 & & & \\
\hline 307 & \multicolumn{6}{|c|}{ Stop infusion } \\
\hline 310 & \multicolumn{6}{|c|}{$\begin{array}{l}\text { Start postdiuretic } \\
\text { dialysis }\end{array}$} \\
\hline 328 & & & & B3 & 0 & -2 \\
\hline 372 & B2 & +13 & +3 & & & \\
\hline
\end{tabular}

the group II experiment, which showed no inhibition of sodium transport, was obtained at a time which corresponded closely with the diuretic sample obtained after $305 \mathrm{~min}$ in the group I study.

The presence of a sodium transport inhibitor in plasma of dogs in this study could be incidental to some effect of volume expansion and does not necessarily imply a cause and effect relationship between the factor and the natriuresis of acute saline loading. It has been shown that acute infusions of saline result in alterations of peritubular physical factors which inhibit tubular sodium reabsorption and which may account for saline diuresis $(26,27)$. Furthermore, organ ablation studies have shown that neither the head nor any other organ is necessary for the occurrence of natriuresis after saline loading $(9,28)$. Thus, a natriuretic hormone may not be necessary to account for the diuresis of acute saline loading. However, the depression of tubular sodium reabsorption, demonstrated during deoxycorticosterone (DOCA) escape (29) and hyperoncotic albumin infusion $(30,31)$, does not appear to be associated with 
the same dilutional and hemodynamic changes which accompany massive saline infusions. Additional studies will be necessary to determine whether the factor demonstrated in our studies plays a role in either of these situations or in any of the other as yet unexplained natriuretic states.

The relationship between the factor demonstrated in these studies and possible natriuretic factors demonstrated by others cannot be ascertained with certainty. However, the present results indicating a low molecular weight factor which inhibits active sodium transport in amphibian epithelium in vitro, and having a higher concentration in jugular vein blood appear similar to those of Cort et al. (11). Bricker et al. (32) have demonstrated a factor in uremic plasma that inhibits $P$-aminohippuric acid $(\mathrm{PAH})$ transport in renal cortical slices, and which may be an inhibitor of several tubular transport systems and possibly a natriuretic hormone. The low molecular weight of their factor is similar to that of ours, and in addition, these investigators have recently reported that their factor inhibits frog skin and red cell sodium transport (33).

Several prostaglandins have been shown to cause natriuresis (34), and Lee and Ferguson have suggested that one of these might function as a natriuretic hormone (35). It seems unlikely that the factor demonstrated in these studies is a prostaglandin since $\mathrm{PGE}_{1}$ has been shown to increase rather than inhibit sodium transport in the frog skin in vitro $(36,37)$. Sealey, Kirshman, and Laragh (38) have reported a humoral substance in volume-expanded rats that causes natriuresis when injected into the renal artery of water-loaded rats with diabetes insipidus. The molecular weight of this factor of approximately 50,000 seems to distinguish it as a different substance from that demonstrated in these studies.

\section{ACKNOWLEDGMENTS}

We are grateful to Dr. Joseph S. Handler and Dr. R. I. Keimowitz for assistance, and Dr. Walter Bloom and Dr. E. Converse Peirce for loan of equipment. We thank Dr. Elbert Tuttle, Jr., for much helpful support and for reviewing the manuscript. We also thank Karen Oglund, Marjorie Walters, and Judith Huie for performing the chemical determinations, and Audrey Bohnengel for technical assistance.

This work was supported by grants from the Georgia Heart Association, the American Heart Association, and the National Institutes of Health (AM 05561 and FR 5364). Dr. Green was supported by a summer student research fellowship (NIH General Research Support Grant FR 5364 .

\section{REFERENCES}

1. Smith, H. W. 1957. Salt and water volume receptors: an exercise in physiologic apolgetics. Amer. J. Med. 23: 623 .
2. de Wardener, H. E., I. H. Mills, W. F. Clapham, and C. J. Hayter. 1961. Studies on the efferent mechanism of the sodium diuresis which follows the administration of intravenous saline in the dog. Clin. Sci. (London). 21: 249.

3. Levinsky, N. G., and R. C. Lalone. 1963. The mechanism of sodium diuresis after saline infusion in the dog. J. Clin. Invest. 42: 1261.

4. Wright, F. S., B. M. Brenner, C. M. Bennett, R. I. Keimowitz, R. W. Berliner, R. W. Schrier, P. J. Verroust, H. E. de Wardener, and H. Holzgreve. 1969. Failure to demonstrate a hormonal inhibitor of proximal sodium reabsorption. J. Clin. Invest. 48: 1107.

5. Johnston, C. I., and J. O. Davis. 1966. Evidence from cross circulation studies for a humoral mechanism in the natriuresis of saline loading. Proc. Soc. Exp. Biol. Med. $121: 1058$.

6. Lichardus, B., and J. W. Pearce. 1966. Evidence for a humoral natriuretic factor released by blood volume expansion. Nature (London). 209: 407.

7. Bahlmann, J., S. J. McDonald, M. G. Ventom, and H. E. de Wardener. 1967. The effect on urinary sodium excretion of blood volume expansion without changing the composition of blood in the dog. Clin. Sci. (London). 32: 403.

8. McDonald, M., R. W. Schrier, and D. P. Lauler. 1967. Effect of acute extracellular volume expansion on cross circulated dogs. Nephron. 4: 1.

9. Levinsky, N. G. 1966. Nonaldosterone influences on renal sodium transport. Ann. N. Y. Acad. Sci. 139: 295.

10. Pearce, J. W., B. Lichardus, H. Sonnenberg, and A. T. Veress. 1969. Interaction of intrarenal and extrarenal factors in the natriuresis of volume expansion. Abstracts of the 4th International Congress of Nephrology. 2: 172.

11. Cort, J. H., T. Dousa, V. Pliska, B. Lichardus, J. Safarova, M. Vranesic, and J. Rudinger. 1968. Saluretic activity of blood during carotid occlusion in the cat. Amer. J. Physiol. 215: 921.

12. Rector, F. C., Jr., M. Martinez-Maldonado, N. A. Kurtzman, J. C. Sellman, F. Oerther, and D. W. Seldin. 1968. Demonstration of a hormonal inhibitor of proximal tubular reabsorption during expansion of extracellular volume with isotonic saline. J. Clin. Invest. 47: 761.

13. Hunt, J. R., J. H. Sadler, J. H. Shinaberger, and P. M. Galletti. 1968. Laboratory and clinical evaluation of a small counter-current dialyzer, the miniklung. Trans. Amer. Soc. Artificial Internal Organs. 14: 109.

14. Galletti, P. M. 1966. Theoretical considerations about artificial kidneys. Proc. 3rd Int. Congr. Nephrol. 3: 237.

15. Blatt, W. F., B. G. Hudson, S. M. Robinson, and E. M. Zipilivan. 1967. Fractionation of protein solutions by membrane partition chromatography. Nature (London). 216: 511 .

16. Zall, D. M., D. Fisher, and M. Q. Garner. 1956. Photometric determination of chlorides in water. Anal. Chem. 28: 1665 .

17. Kessler, G., and M. Wolfman. 1964. An automated procedure for the simultaneous determination of calcium and phosphorous. Clin. Chem. 10: 686.

18. Hoffman, W. S. 1937. A rapid photoelectric method for the determination of glucose in blood and urine. J. Biol. Chem. 120: 51 .

19. Finn, A. L., J. S. Handler, and J. Orloff. 1967. Active chloride transport in the isolated toad bladder. Amer. J. Physiol. 213: 179. 
20. Leaf, A., J. Anderson, and L. B. Page. 1958. Active sodium transport by the isolated toad bladder. J. Gen. Physiol. 41 : 657.

21. Snedecor, G. W. 1956. Statistical Methods. The Iowa State University Press, Ames.

22. Frazier, H. S., and A. Leaf. 1963. The electrical characteristics of active sodium transport in the toad bladder. J. Gen. Physiol. 46: 491.

23. Alexander, R. W., and P. M. Galletti. 1965. The transfer of macromolecules in an artificial kidney. Trans. Amer. Soc. Artificial Internal Organs. 11: 95.

24. Maffly, R. H., and I. S. Edelman. 1963. The coupling of the short circuit current to metabolism in the urinary bladder of the toad. J. Gen. Physiol. 46: 733.

25. Crabbe, J. 1961. Stimulation of active sodium transport by the isolated toad bladder with aldosterone in vitro. J. Clin. Invest. 40: 2103.

26. Martino, J. A., and L. E. Earley. 1967. Demonstration of the role of physical factors as determinants of the natriuretic response to volume expansion. J. Clin. Invest. 46: 1963

27. Earley, L. E., and T. M. Daugharty. 1969. Sodium metabolism. N. Engl. J. Med. 281: 72.

28. Johnston, C. I., J. O. Davis, S. S. Howards, and F. S. Wright. 1967. Cross-circulation experiments on the mechanism of natriuresis during saline loading in the dog. Circ. Res. 20: 1.

29. Wright, F. S., F. G. Knox, S. S. Howards, and R. W. Berliner. 1969. Reduced sodium reabsorption by the proximal tubule of DOCA-escaped dogs. Amer. J. Physiol. 216: 869.
30. Knox, F. G. 1969. Rejection of sodium in the distal nephron following chronic salt retention. Abstracts of the 4th International Congress of Nephrology. 1: 326.

31. Brenner, B. M., K. H. Falchuk, R. I. Keimowitz, and R. W. Berliner. 1969. Relationship between peritubular capillary protein concentration and fluid reabsorption by the renal proximal tubule. J. Clin. Invest. 48: 1519.

32. Bricker, N. S., S. Klahr, M. Purkerson, R. G. Schultze, L. V. Avioli, and S. J. Birge. 1968. In vitro assay for a humoral substance present during volume expansion and uremia. Nature (London). 219: 1058.

33. Bricker, N. S., S. Klahr, J. Bourgoignie, C. L. Miller, and H. A. Lubowitz. 1969. On a circulating inhibitor of sodium transport in uremia. Abstracts of the 4th International Congress of Nephrology. 2: 173.

34. Johnston, H. H., J. P. Herzog, and D. P. Lauler. 1967. Effect of prostaglandin $\mathrm{E}_{1}$ on renal hemodynamics, sodium and water excretion. Amer. J. Physiol. 213: 939.

35. Lee, J. B., and J. F. Ferguson. 1969. Prostaglandins and natriuresis: the effect of renal prostaglandins on $\mathrm{PAH}$ uptake by kidney cortex. Nature (London). 222: 1185.

36. Fassina, G., F. Carpendo, and R. Santi. 1969. Effect of prostaglandin $E_{1}$ on isolated short-circuited frog skin. Life Sci. 8: 181.

37. Barry, E., and W. J. Hall. 1969. Stimulation of sodium movement across frog skin by prostaglandin $\mathrm{E}_{1}$. J. Physiol. (London) . 200: 83P.

38. Sealey, J. E., J. D. Kirshman, and J. H. Laragh. 1969. Natriuretic activity in plasma and urine of salt loaded man and sheep. J. Clin. Invest. 48: 2210. 